A publication of the Muma College of Business | University of South Florida

\title{
HOW TO GROW REVENUES IN AN UNCERTAIN WORLD? ${ }^{1}$
}

\author{
Do I bet on a new product in proven markets or a proven product in new markets?
}

It was Friday afternoon and Rob Hammond, product executive for enterprise products at Syniverse, was sitting at his desk reviewing the draft board presentation that would be delivered next week. The first section of the draft presentation described the current enterprise SMS market--Hyper Competitive; the next section reviewed the company's positioning--Vulnerable to Commodization; and the final section was blank, titled--Product Investments: Development Prioritization and Sales Training. Should Rob invest in sales efforts to promote Syniverse' new value added enterprise product, or instead leverage Syniverse' past success to pursue high growth emerging markets--like India, Southeast Asia, Latin America, and Greater China? These markets continued to grow rapidly and remained robust growth prospects for at least the next five years. To make an impact in the coming fiscal year, Rob had to focus organization efforts now in order to align the product development plans with sales training and distribution.

The presentation weighed heavy on Rob’s mind. It wasn't the presentation or the meeting that was bothering him; it was that Rob had lived through maturing technology markets before. He had seen market leaders harvest profits and fail to recognize deteriorating market conditions. The problems manifested themselves as intense pricing pressure and compressing margins driven by competitors fighting to maintain share. Large companies had begun to connect directly to major telecommunication carriers and in markets where the businesses used a company like Syniverse to aggregate the carrier connections, the large business customers had begun using reverse auctions to drive prices down.

Fortunately for Syniverse, its business customers were also beginning to use mobile technologies for more than simple text notifications. Businesses were experimenting with connecting enterprise applications (CRM, ERP, Loyalty, Customer Service) to native mobile apps, media on mobile web sites, and text messaging. Syniverse had experienced some success in the United States in providing a cloud solution to retail, financial services, travel, and hospitality companies. The new product made integrating to the enterprise application and delivering the mobile experience across all of the different mobile channels much simpler. This was particularly attractive to non-technical line of business decision makers, as the service required little of the customer technology team's involvement and could usually be implemented without capital project prioritization by the customer. Most of Syniverse' new product sales had been delivered by two of the sales people, and Rob knew training the sales teams would be critical to deliver the revenue. So, Rob needed to decide what to present to the board. Did he focus the company on the products it knew, expanding the existing text messaging business into high growth mobile markets, or did he invest in expanding the new product of enabling mobile for business applications?

\footnotetext{
${ }^{1}$ Copyright (c) 2017, Rob Hammond. This case was prepared for the purpose of class discussion, and not to illustrate the effective or ineffective handling of an administrative situation. Names and some information have been disguised. This case is published under a Creative Commons BY-NC license. Permission is granted to copy and distribute this case for non-commercial purposes, in both printed and electronic formats.
} 


\section{The Mobile Industry}

The mobile industry was massive and growing. The global mobile industry group, GSMA, reported in its “The Mobile Economy 2014” that mobile ecosystem revenues consisting of network infrastructure, components, applications, content, advertising, device and mobile operator revenues were almost \$2 trillion USD (see Exhibit 1) (GSMA, 2014). This would include all of the operator revenues, device sales, application sales, mobile advertising, and various derivative services. The $\$ 2$ trillion was expected to grow to almost $\$ 2.9$ trillion with applications, content, and advertising becoming $16 \%$ of the total revenues by 2020. In total there were roughly 7 billion connected devices or 1.2 connections per subscriber in 2013. Additional information on the mobile industry is available in Exhibit 2, "Key Telecom Indicators for the World Telecommunication Service Sector in 2014" and Exhibit 3, "Number of Mobile Users in Asia-Pacific region from 2011 to 2018.”

With the growth in mobile revenues and mobile connections as shown in Exhibit 4, it was no surprise that companies were also beginning to find ways to connect with mobile phone users. Companies embraced the mobile web and first tried to "shrink down" the desktop web experiences for mobile. These efforts were moderately successful but had challenges. Mobile device screens were smaller and the types of information users sought was different in mobile than on the traditional web.

Next, companies deployed native applications. There were two significant app stores: one that supported the Apple iPhone devices and one that worked with Google's Android operating system. The two app stores were iTunes and Google Play. By 2014 there were literally millions of applications in the app stores and users had begun to show signs of app exhaustion. Apps required a user's attention. Apps needed sign in, required updates, occupied storage and screen real estate. Some users would use a company's app but usage rates typically plummeted after a short period and by six months a company would have fewer than $5 \%$ of its customers using the app regularly. Worse yet, mobile application maintenance costs and mobile application user acquisition costs were climbing. In 2014 the cost for new app install and engagement costs were up 50\% and 33\% year over year. This trend was likely to continue as user expectations rose (Berney, Hammond, \& Lee, 2015).

The third alternative for engaging users was to use text messaging also known as SMS. SMS was an abbreviation for Short Message Service and had been commercially available since the 1990's. By 2014, SMS was being used routinely by companies for many different purposes. Due to consumer's affinity for their phones, SMS had become one of the standard methods for ensuring identity. Many companies had started using SMS and the mobile phone as the second factor in a two factor authentication system. Another common application was to use SMS to notify a customer of key transactions. Shipping notification, appointment changes, and itinerary changes were just a few of the typical applications. SMS was also used for promotions. Various retailers were finding success with coupons and discounts delivered via SMS. By 2014, SMS had become a commonplace solution for promotions, transaction notifications, loyalty cards, and customer service applications.

Even with the expansion in consumer mobile use, companies had problems updating their enterprise applications to be able to support mobile. Many of the major enterprise applications like CRM, ERP, and other custom built solutions were created during the late 1990s in the dot-com boom. The state-of-the-art at the time was a shared user computer with a wired connection. The underlying data schema of these systems was not built with the concept of users being connected on multiple devices simultaneously while talking to a sales person in a store. The systems were also typically deployed in the company's data centers and were deeply engrained in the company's business operations. Changes to these systems were a complex undertaking requiring substantial financial and people resources. The opportunity cost for these projects was also very high as many internal groups competed for project priority and constrained resources. Nonetheless, mobile was an enormous market disruption and opportunity. When commenting 
on mobile as a technology disruption, Rob stated, "Mobile was pervasive and impacted every facet of the customer journey. Mobile is to the internet as the internet was to brick and mortar."

\section{Syniverse}

Syniverse was a pioneer in the mobile industry. Syniverse grew up with the mobile telecommunication companies and had a long history of providing services to the world's telecommunication companies. In fact, Syniverse sales teams would routinely quote the number of telecommunication companies, 1,000, that purchased services from Syniverse. What was less well known was that Syniverse also provided services, primarily SMS, to over 500 enterprise customers. In total Syniverse had customers in over 200 countries and territories, and served these customers with more than 2,500 employees. Customers came from virtually every industry including: financial services, retail, hospitality, travel, technology, and social networks. The following explanation of mobile solutions was from the Syniverse website (www.syniverse.com):

Syniverse makes mobile work for mobile operators, cable and Internet providers, and enterprises as well as M2M, VoIP and application service provider companies around the world. We make seamless communications between operators, technologies, devices and networks possible for mobile users around the globe. With unmatched expertise and more than 25 years simplifying the complexities of roaming, messaging and networking, Syniverse serves as the force at the center of the mobile communications universe, keeping people connected today and forging new connections for tomorrow. Nobody knows mobile solutions like Syniverse.

Exhibit 5 summarizes Syniverse’ office locations. Syniverse’ Corporate Headquarters was in Tampa, FL and regional headquarters were in the following locations:

- Asia Pacific: Hong Kong

- Caribbean and Latin America: Buenos Aires, Argentina

- Europe: Luxembourg

- Middle East and Africa: Dubai, United Arab Emirates

\section{Syniverse Organization}

Syniverse shared development and operations between two product groups: Mobile Transaction Services (MTS) and Enterprise Intelligence Services (EIS). Customer management functions (Sales, Client Management and Solution Engineering), and product functions were separated between the two groups.

\section{Syniverse SMS Service}

Syniverse began in the enterprise market by acquiring the enterprise SMS messaging business from Verisign. In this business Syniverse provided 2-way SMS services for companies that wanted to deliver and receive text messages with end customers. The industry called this service A2P which was an abbreviation for Application to Peer messaging. Peer to Peer messaging or P2P was when two people exchanged messages with each other. To ensure consumers did not receive unwanted messages from overzealous companies, the telecommunication carriers in the United States implemented special rules for A2P messaging. A sample of these rules is shown in Exhibit 6. Other countries also implemented various rules that included time of day routing, special approvals by customers to receive messages, and substantial fines for companies that broke the rules. 
This ecosystem created an entire industry of its own to aggregate the network connections for an enterprise, allowing that enterprise to greatly reduce the number of required network connections and providing assistance in navigating the increasingly complex world of global messaging. Rob felt that Syniverse was a global leader in this area with few competitors that could match Syniverse' global reach and focus on customer service.

In addition to navigating the complex regulatory landscape, aggregators provided a much simpler interconnection alternative for companies. It was sometimes necessary to illustrate the number of connections a company would require to get the required customer reach. Exhibit 7 helped to explain the connections. A company would require one (two for redundancy) connection to Syniverse as opposed to one connection for every operator (two for redundancy). In the United States there were four large nationwide carriers that represented 99\% of the United States mobile subscribers (Team, 2014). A company would need a total of one connection to Syniverse or four connections to the carriers. Beyond the connections the company would also have to file paperwork and implement with every carrier as well. From his past experience in telecommunications, Rob knew this was an enormous strategic advantage for Syniverse, and would comment to customers and analysts when explaining Syniverse' significance as an aggregator that, "No one company reaches $100 \%$ of the market by themselves, no one. No social network, no communications provider. No one."

SMS provided fundamental advantages over other communication technologies. Some of the advantages included:

- $90 \%$ of all text messages were read within three minutes of delivery.

- Enterprises that used SMS could reach 95\% of the world's mobile users.

- Most adults considered an SMS as meaningful as a voice conversation.

Mahindra Comviva \& Ovum Research reported that the outlook for SMS was quite positive. The period of 2013 through 2017 would mark a golden age for A2P SMS. Ovum expected A2P SMS traffic to peak at 2.2 trillion messages with operators and third-party service providers launching a range of services across verticals that utilized A2P SMS for service initiation, control, or monitoring (Comviva, 2014).

A2P would grow at a rate of 6\% CAGR 2013-2018. In 2013, the world would have transacted over 1.6 trillion A2P messages, and this would grow to 2.19 trillion A2P messages by 2018. Currently, feature phones outnumbered smartphones, therefore any consumer facing service that wanted to have the widest possible reach must utilize SMS as a channel.

\section{Syniverse Mobile Engagement}

A newer part of Syniverse' enterprise offering was its Mobile Engagement product. Syniverse Mobile Engagement provided a company with a flexible Graphical User Interface (GUI) that non-technical business people could use to create rich mobile interactions. The tool supported SMS, MMS (a multimedia version of SMS), email, native applications, and voice interactions. New approaches for applications like Apple's Passbook were also available. The product provided a two way Application Programing Interface (API), so it could be connected directly to an enterprise application. Having an API was critical as it provided a mechanism for the company to maintain the data in its legacy system and automate transmitting data to Syniverse. Essentially, Syniverse Mobile Engagement became an extension of the company's information technology infrastructure. Some of the common use cases were global reservation confirmation, loyalty program notifications, surveys, and coupon promotions. It was also possible to combine shortened URLs to provide customer's a way to reach rich content on the web like 
video and responsive web pages. A copy of the Syniverse product sheet for Mobile Engagement has been provided in Exhibit 8.

A key part of the value of Syniverse' Mobile Engagement solution was Syniverse' business model that provided a company's business executives a no capital approach to getting a mobile service up and running. The Syniverse solution provided both an API as well as a file upload option for getting data into the platform. Syniverse would then provide the functionality as a cloud service. This approach allowed a company's business leaders to use operating and marketing budgets to provide new services to their customers without involving IT resources and prioritization. It was common to begin quickly with the line for business executives, and once success was established to move to a more integrated solution that included the company's IT department and API integration to Enterprise Applications. With Syniverse' work in the Financial Services industry, Syniverse was able to routinely address security and privacy questions.

A second element of differentiation for Syniverse was its strategy of providing a complete customer experience and enriching that experience with mobile context. The complete customer experience meant providing everything the marketing or customer service buyer required to deliver the service. Syniverse would host web sites, provide training, and even hire a creative agency to enable a company to deliver on its planned solution. There were five different types of mobile context as described by Rob Hammond in an article that was published by the trade journal Mobile FOMO (Hammond, 2015).

- Physical context: Physical context was the category that was commonly meant when context was used in the generic form. Physical context described a consumer's location.

- Temporal context: Temporal context was the collection of contextual elements that explained what a person was doing at any moment. Examples could be standing in line or playing a game.

- Personal context: Personal context included a person's preferences, identity, and relationships. Preferences could either be provided explicitly by a consumer or inferred through interactions.

- Psychological context: Psychological context was what a person aspired to be or do. This was different from historical context that described what a person has done.

- Historical context: Historical context described what a person has done. Enterprise applications were filled with historical context in the form of transaction data.

Market research has shown that mobile context was important (Berney, et al., 2015).

- $\quad 30 \%$ of US consumers didn't use apps because offers weren't contextual.

- $80 \%$ of smartphone owners wanted more mobile-optimized info while shopping.

- $23 \%$ of smartphone owners expected mobile experiences to change based on location.

- Click-through rates for location-based offers was $4 x$ greater than offers without location context.

- $84 \%$ of mobile users actively used smartphones when shopping.

- Mobile app usage increased 16 times while shopping in-store.

\section{Syniverse Sales Process}

Enterprise sales teams reported to a regional sales manager who in turn reported to a global sales leader. A typical sales team consisted of an account manager, client manager, and solution engineer. The sales person was responsible for revenue, the client manager managed the day-to-day account activities, and the solution engineer provided presales technical support. Account managers had varied backgrounds and approaches to selling. Sales people mostly came from the telecommunications area vertically. They were well versed in the SMS technology. 
Sales leads came to Syniverse through many different paths including existing customer expansion, web visits, web events, conference attendance/speaking, contact referral, Request for Proposals (RFPs), and white space lead generation activities. As the market leader in text messaging, Syniverse was well known by anyone seeking messaging solutions in the U.S. and Europe. Depending on the customer's readiness to take action, a text messaging contract could progress rapidly, and be signed within a couple of weeks and at times in a just a couple of days. The buying decision was usually made by a sourcing group or manager, and consisted of receiving bids from several providers and then selecting the cheapest route that delivered the requisite quality.

In stark contrast a Mobile Engagement sale would occur over the span of several months involving the senior line of business executives. In addition, given the type of data and application integration involved, a separate technical discussion track was required before a price could be fully determined. A simple mobile engagement contract would take three months, and more complex contracts could easily extend multiple quarters. The mobile engagement sale usually included several presentations, assistance with a business case, and a trial before executing a contract. References were often important as line of business executives needed reassurance that the solution would in fact address the underlying customer need.

\section{Syniverse Challenges}

\section{Text (SMS) Competitors and Gray Routes}

Hammond felt Syniverse was well positioned to deliver global SMS services. The company had a culture of customer support and a proven history of performance. With its close connection to the telecommunication companies, Syniverse was at times disadvantaged due to competitors taking advantage of the gray and not-so-gray areas of regulations. Some competitors were known to use what the industry called "gray routes" to send messages. Gray routes were message paths that had not been contracted by the carriers. A gray route messaging provider would find gaps in the carrier networks and blend the gray route traffic with high quality contracted routes. By not paying for the gray route traffic, a competitor would be able to offer a lower price to a company. The gray routes were ultimately discovered, but usually not before the competitor had won the contract and implemented the connection. Sometimes these questionable actions by competitors created pricing pressure for Syniverse. Gray routes were more than a financial problem. Companies were often unaware that messages were not being delivered, and thus a company’s customers did not receive critical messages.

\section{Evolving Types of Aggregators and Wholesale}

Additional pricing pressure was being created by new wholesale entrants, and some of Syniverse' customers themselves began acting like aggregators. Companies with large volumes were beginning to connect directly to carriers on the highest traffic routes. This reduced Syniverse volumes, eroding scale economics on the impacted routes.

Interestingly, Syniverse was a major wholesale provider itself. This was important for Syniverse as the additional volume helped ensure preferred global pricing, but at the same time the wholesale business enabled competitors. In much the same way a company could connect to Syniverse and reach the world's 1000 operators, so too could a competitor. Essentially, with just a couple of data connections a competitor could provide global services, and claim the same global reach as Syniverse overnight.

\section{Text (SMS) Delivery in Markets with Regulatory Constraints}

Syniverse also had challenges with global reach in certain markets where regulatory constraints made it difficult for a multinational to do business. These regulations had necessitated strategic partnering with 
some local companies which in turn added complexity to the business. Brand recognition was a challenge in the global marketplace especially in emerging price conscious markets.

\section{Brand Recognition}

Mobile Engagement brought new challenges to Syniverse. Again Syniverse' strong telecommunication relationships and customer centric support were valuable assets, but in the enterprise application market Syniverse had little brand recognition. Mobile Engagement sales were being made to the line of business leaders in marketing and customer service. These customers were different from anything Syniverse had seen before. The Syniverse sales force was accustomed to sourcing departments and professional negotiators, but these customers expected vertical expertise and solutions to vertical specific problems along with references.

\section{Mobile Engagement Competitors}

Competitors for SMS and Mobile Engagement were equally different. SMS competitors were well known and in fact listed on the U.S. Short Code registry web site (see Exhibit 9). Quite the opposite, Mobile Engagement competitors were vast and unique. There were the enterprise application providers like Oracle, SAP, Salesforce/Exact Target, and IBM along with marketing companies like Marketo and Adobe. Then there were small niche firms who specialized in a unique solution or early adoption technology. Syniverse' scale, longevity, and business model resonated with customers as the company had successfully taken business from both the niche and enterprise scale companies. Exhibit 10 displayed a Syniverse infographic that highlighted key areas to consider when selecting a mobile messaging provider.

\section{Global Delivery}

While global in delivery, the majority of Syniverse Mobile Engagement customers were US multinationals. Syniverse was in advanced discussions with companies around the globe and was considering various channel approaches for Mobile Engagement. Syniverse also had other enterprise products that it had launched and sold globally.

\section{Marketplace Focus on Native Applications}

A final challenge for Syniverse was the marketplace was deeply enamored with native mobile applications. Company's typically thought of their web sites and mobile apps as the primary tools to engage customers. SMS was often left out of the marketing plans.

\section{Sales Training}

Rob had two large white boards in his office. On one of the white boards Rob had three columns. The columns were titled, Innovation Diffusion, Motivation, and the third was Informing Science. Rob wondered, "What's the best way to think about training and motivating the sales teams? Was this a case of Innovation Diffusion?” If so, then Rob needed to focus on the change agents and identifying early adopters. Or perhaps, this was simply a case of motivation. If the problem was motivation, then intrinsic and extrinsic motivation would be effective. But maybe it was an Informing Science problem and this was a complex landscape. To help think through the problem, Rob reviewed various business theories research and created the following summaries. 


\section{Innovation Diffusion}

Innovation Diffusion presented an alternative to explain the limited sales person success in selling the new product as well as suggesting a framework for identifying potential challenges in adoption. Innovation Diffusion explained that people would adopt an innovation at different rates. Plotting the population's rate of adoption, the distribution was a standard "bell” curve. Innovation Diffusion has been observed in different cultures and across industries. A population could be divided into five innovation adoption categories:

- Innovator

- Early Adopter

- Early Majority

- Late Majority

- Laggards

When plotting innovation adoption for the entire population against time, the resulting plot resembled an "S" laying on its side. Research suggested that one of the parameters that affected innovation adoption was the amount of interaction an individual had outside of the population. This attribute was called cosmopolitan versus localite. More cosmopolitan resources tended to adopt earlier and could be influenced by mass media communications. Localite resources tended to adopt later and required first hand evidence of the innovation success before adopting. Other things that could impact the rate of adoption were how easily the innovation could be trialed and how easily the result of the innovation could be observed. One often used tactic to accelerate innovation adoption was to introduce a change agent to the population. The change agent worked in the population to instruct, understand objections, and suggest approaches to mediate concerns (Rogers, 2010).

If Innovation Diffusion was the primary theory, then the following tactics could be considered as approaches to accelerating change:

- Introducing a change agent to work with the sales force on adoption of the innovation

- Enhancing observability by highlighting the internal resources who had success selling mobile engagement

- Providing opportunities for successful internal sales people to share experiences with sales people who were not successful

- Providing information on selling Mobile Engagement from the mass media

- Improving trialability by implementing compensation programs that minimized loss of compensation when trying to sell the new products

\section{Motivation}

A second theory to consider in the investment decision was Motivation theory. In Motivation theory, people were motivated by different things. Motivations were divided into two categories: intrinsic and extrinsic motivations. Extrinsic motivation was when the motivation comes from outside of the individual. Examples of extrinsic motivation in sales included:

- $\quad$ Special bonus incentives

- Trips

- Unique sales designation (winner circle) logo on business card

- Recognition at sales meetings 
The other category of motivation was intrinsic motivation. Intrinsic Motivation was behavior that was driven by internal rewards. Examples of intrinsic motivation in the sales force would be:

- Pride in solving a customer's problem

- The thrill of being the first person to close a new product sale

Motivation elements were moderated by culture. Different cultures reacted differently to public praise and rewards. In some cultures, it was a great reward to have one's work trumpeted by the sales management in a newsletter or company meeting, whereas for others such behavior would be unthinkable. The diagram in Exhibit 11 demonstrated the complexities of Motivation theory.

\section{Informing Science}

The third theory was Informing Science. Informing Science suggested that each sales person was at a point of fitness based on his/her collective experiences and personality traits. Each sales person has developed his or her unique collection of skills to sell effectively and had these experiences validated by meeting quarterly sales quotas. For Informing Science, this complex landscape therefore mandated that to be effective, the anticipated training would need to address the fact that each sales person was starting from a different point with his/her own unique skill set, and would thus require a personalized unique training journey.

Facts supporting the evidence of Informing Science theory include:

- Points of sales fitness based on resource experiences, success rates, and personalities

- Diverse cultures in emerging markets

- Different products: Mobile Engagement and A2P Messaging

- Different customer problems and uses for Mobile Engagement

The diagrams presented in Exhibit 12 and Exhibit 13 illustrated individual filters and the effect of interacting variables in creating complex landscapes.

\section{Analysis}

On the second white board Rob laid out the key issues for each of the areas, as shown in Exhibit 14. First, overall the company was in a strong position. Syniverse was a strong company with a credible history of delivery. The company was a market leader and had success in both of the products being considered. However, there were also concerns. Syniverse was not well known outside of the telecommunications vertical, regional expansion would stress parts of the company, and then there was the issue of training the sales force. And lastly, there were other options for product distribution or combinations of the products.

\section{Considering the Options}

Rob leaned back in his chair and starred at two full white boards. He underlined the key items that would form the basis of the strategy and presentation.

- $\quad \underline{\text { SMS }}$ provided the greatest reach and usability to contact customers anytime and anywhere.

- SMS was underappreciated by companies. 
- $\underline{\text { SMS }}$ was Syniverse' strategic advantage. Delivering a me-too online and mobile app product that consumers wouldn't use just made no sense. The data and trends were clear and apps were losing steam in the crowded marketplace. Rob was convinced the market was ready to turn.

- Quality, reliable message delivery was going to be the future battleground. Companies couldn't risk their brands on cheap inferior options. Yet, the market also needed to stabilize by addressing the providers who were playing loose with the rules. Rob wrote "WHOLESALE?" in the corner of the board.

- Sales training was absolutely critical. Getting people to sell differently took time: different value propositions, different buyers, and different prices. The structure of the sales plan was set, but incentives were an option.

The options seemed obvious, but the execution, investment, and business trade-offs were anything but obvious.

Option 1: Invest in growing SMS Application to Peer Messaging into the high growth markets. Positives

- Predictable revenue and limited technology risk due to company's experience in the industry.

- Existing sales training, compensation programs, and telecommunication business offices could be leveraged to minimize the efforts associated with regional expansion.

Negatives

- Competitive pressures were growing and commoditization was likely in the future.

Option 2: Invest in moving up the value chain by mobile enabling enterprise applications. Positives

- Highly differentiated value based sale provided protection against commoditization because of the difficulty to dislodge once solution was in production. Sale tightly aligned to customer's business objectives.

Negatives

- Complex sale to largely non-technical line of business executives who did not know the company.

- Required training sales people to sell differently to a different type of customer.

Option 3: Combine Option 1 and Option 2 by leveraging some type of distribution partnership to reduce resource constraints.

Positives

- Best combination of short term revenue and long term market positioning. Near term revenue was relatively predictable, and business challenges were known Negatives given the company's extensive experience with the technology and market.

- Most complex training problem. Every sales person would need to be trained, and different sales skills would need to be incorporated depending on what products they sold and where the sales person was located.

- Placed additional demands on the product organization and support groups. Partners would reduce margins as well as limit the company's ability to sell future products. 
There had to be a way forward. Clearly the company needed to continue its investment in SMS globally, but how could he grow revenues on the existing products, and expand the product portfolio at the same time. Rob thought, "How am I going to train this sales force and position the company for growth?”

\section{References}

Berney, P., Hammond, R., \& Lee, J. (2015). 2016 Mobile engagement trends [Webinar]. Retrieved from https://www.syniverse.com/webinars/2016-mobile-engagement-trends

Comviva, M. (2014). Leveraging the A2P SMS opportunity. Ovum. Retrieved from http://www.mahindracomviva.com/wp-content/uploads/2015/02/A2PSMS WP October2014.pdf

Gill, T. G. (2010). Informing business: Research and education on a rugged landscape. Santa Rosa, CA: Informing Science. Retrieved from http://www.grandon.com/publications/InformingBusiness.pdf

GSMA. (2014). The mobile economy 2014. GSMA Intelligence. Retrieved from http://www.gsma.com/mobileeconomy/archive/GSMA_ME_2014.pdf

Hammond, R. (2015). How the five types of context enrich mobile marketing. Mobile FOMO Mobile Marketing News. Retrieved from http://mobilefomo.com/2015/04/types-context-enrich-mobilemarketing/

Rogers, E. M. (2010). Diffusion of innovations. New York: Simon and Schuster.

Ryan, R. M., \& Deci, E. L. (2000). Intrinsic and extrinsic motivations: Classic definitions and new directions. Contemporary Educational Psychology, 25(1), 54-67. Retrieved from http://www.sciencedirect.com/science/article/pii/S0361476X99910202

Team, T. (2014). Week in review: U.S. wireless carriers. Forbes. Retrieved from http://www.forbes.com/sites/greatspeculations/2014/09/03/week-in-review-u-s-wirelesscarriers/\#99a3ee1358e1

\section{Biography}

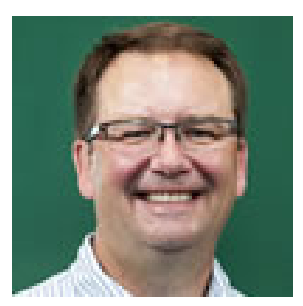

Rob Hammond joined Syniverse in 2013 and has more than 28 years of global leadership experience in enterprise strategy, product management, sales and engineering, with a special focus in mobile and enterprise applications. As Senior Director of Mobile Engagement, Rob is one of the leaders in Syniverse's Enterprise and Intelligence Solutions, the business unit that enables brands and mobile service providers to better engage mobile users. During his tenure at Syniverse, Rob has helped lead the development of products from inception to launch for such areas as A2P messaging, campaign management and fraud prevention. Prior to Syniverse, he served in leadership roles for several of the world's largest mobile and technology companies, including Microsoft, Sprint and Motorola. Rob is currently a doctoral candidate at the Muma School of Business, University of South Florida, with expected graduation in 2017. He also holds a Master of Business Administration, a Master of Science in Engineering, and a Bachelor of Science in Electrical Engineering.

Source: Rob Hammond's biography as it appeared in the trade magazine Mobile FOMO. 


\section{Exhibit 1: Mobile Ecosystem Total Revenue Forecasts}

Source: GSMA Intelligence

Mobile ecosystem total revenue forecasts

(US\$ Bn)

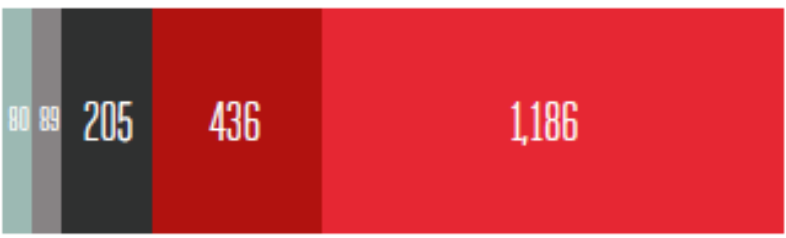

2013

US\$ $1,996 \mathrm{Bn}$

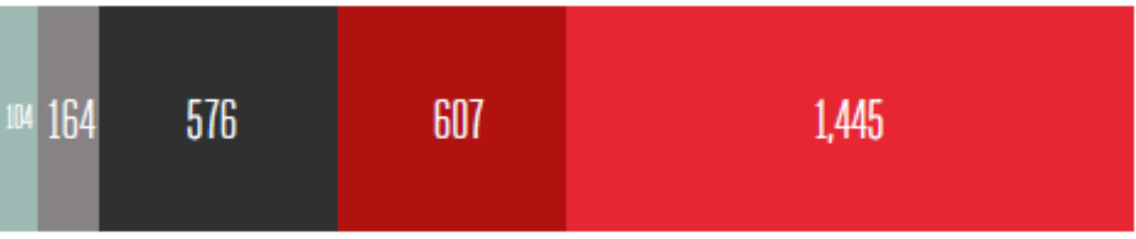

2020

US\$ 2,897 Bn

PETWORK

NERASTRUCTUPE $O$ COMPONENTS

32 I Global market overview

Source: http://www.gsma.com/mobileeconomy/archive/GSMA ME 2014.pdf 


\section{Exhibit 2: Key Telecom Indicators for the World Telecommunication Service Sector in 2014}

\begin{tabular}{|c|c|c|c|c|c|c|c|c|c|}
\hline & Global & $\begin{array}{l}\text { Developed } \\
\text { nations }\end{array}$ & $\begin{array}{l}\text { Developing } \\
\text { nations }\end{array}$ & Africa & $\begin{array}{l}\text { Arab } \\
\text { States }\end{array}$ & $\begin{array}{l}\text { Asia \& } \\
\text { Pacific }\end{array}$ & CIS & Europe & $\begin{array}{l}\text { The } \\
\text { Americas }\end{array}$ \\
\hline $\begin{array}{l}\text { Mobile cellular } \\
\text { subscriptions } \\
\text { (millions) }\end{array}$ & $6,915 \mathrm{~m}$ & $1,515 \mathrm{~m}$ & $5,400 \mathrm{~m}$ & $629 \mathrm{~m}$ & $410 \mathrm{~m}$ & $3,604 \mathrm{~m}$ & $397 m$ & $780 \mathrm{~m}$ & $1,059 \mathrm{~m}$ \\
\hline Per 100 people & $95.5 \%$ & $120.8 \%$ & $90.2 \%$ & $69.3 \%$ & $109.9 \%$ & $89.2 \%$ & $140.6 \%$ & $124.7 \%$ & $108.5 \%$ \\
\hline $\begin{array}{l}\text { Fixed telephone } \\
\text { lines } \\
\text { (millions) }\end{array}$ & $1,147 \mathrm{~m}$ & $511 \mathrm{~m}$ & $636 \mathrm{~m}$ & $12 \mathrm{~m}$ & $33 m$ & $512 \mathrm{~m}$ & $70 \mathrm{~m}$ & $245 m$ & $256 \mathrm{~m}$ \\
\hline Per 100 people & $15.8 \%$ & $40.8 \%$ & $10.6 \%$ & $1.3 \%$ & $8.7 \%$ & $12.7 \%$ & $24.9 \%$ & $39.2 \%$ & $26.3 \%$ \\
\hline $\begin{array}{l}\text { Active mobile } \\
\text { broadband } \\
\text { subscriptions } \\
\text { (millions) }\end{array}$ & $2,315 \mathrm{~m}$ & $1,050 \mathrm{~m}$ & $1,265 \mathrm{~m}$ & $172 \mathrm{~m}$ & $92 m$ & $920 \mathrm{~m}$ & $138 \mathrm{~m}$ & $399 m$ & $577 \mathrm{~m}$ \\
\hline Per 100 people & $32.0 \%$ & $83.7 \%$ & $21.1 \%$ & $19.0 \%$ & $24.6 \%$ & $22.8 \%$ & $48.9 \%$ & $63.8 \%$ & $59.1 \%$ \\
\hline $\begin{array}{l}\text { Mobile } \\
\text { broadband } \\
\text { growth } \\
\text { 2013-14 }\end{array}$ & $\mathrm{N} / \mathrm{A}$ & $11.5 \%$ & $26 \%$ & $43 \%$ & $19 \%$ & $21 \%$ & $15 \%$ & $12 \%$ & $16 \%$ \\
\hline $\begin{array}{l}\text { Fixed broadband } \\
\text { subscriptions } \\
\text { (millions) }\end{array}$ & $711 \mathrm{~m}$ & $345 \mathrm{~m}$ & $366 \mathrm{~m}$ & $3 m$ & $12 \mathrm{~m}$ & $313 m$ & $40 \mathrm{~m}$ & $173 \mathrm{~m}$ & $163 \mathrm{~m}$ \\
\hline per 100 people & $9.8 \%$ & $27.5 \%$ & $6.1 \%$ & $0.4 \%$ & $3.1 \%$ & $7.7 \%$ & $14.3 \%$ & $27.7 \%$ & $16.7 \%$ \\
\hline
\end{tabular}

Source: @ International Telecommunication Union (May 2014)

via: (๑) mobiThinking

Source: https://mobiforge.com/research-analysis/global-mobile-statistics-2014-part-a-mobile-subscribershandset-market-share-mobile-operators 
Exhibit 3: Number of Mobile Users in Asia-Pacific Region from 2011 to 2018 (in Millions)

Number of mobile phone users in the Asia-Pacific region from 2011 to 2018 (in millions)

This forecast shows the number of mobile phone users in the Asia-Pacific region from 2011 to 2018. In 2012, there were approximately 2.27 billion mobile users, which is expected to increase to almost 3 billion by 2017 .

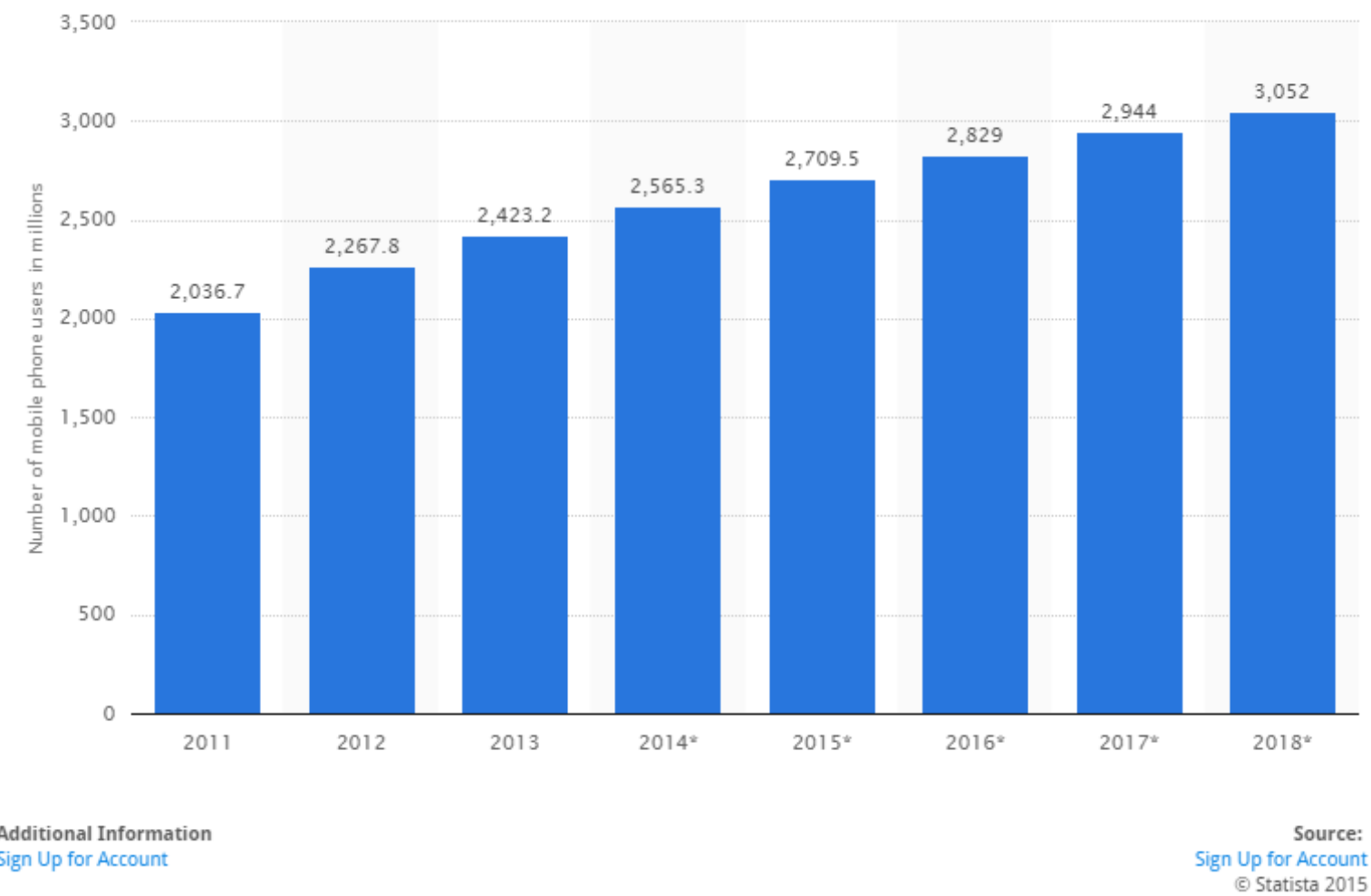

Source: https://www.statista.com/statistics/201250/forecast-of-mobile-phone-users-in-asia-pacific/ 


\section{Global Mobile Connections}

( $\mathrm{m}$, excluding $\mathrm{M} 2 \mathrm{M}$ )

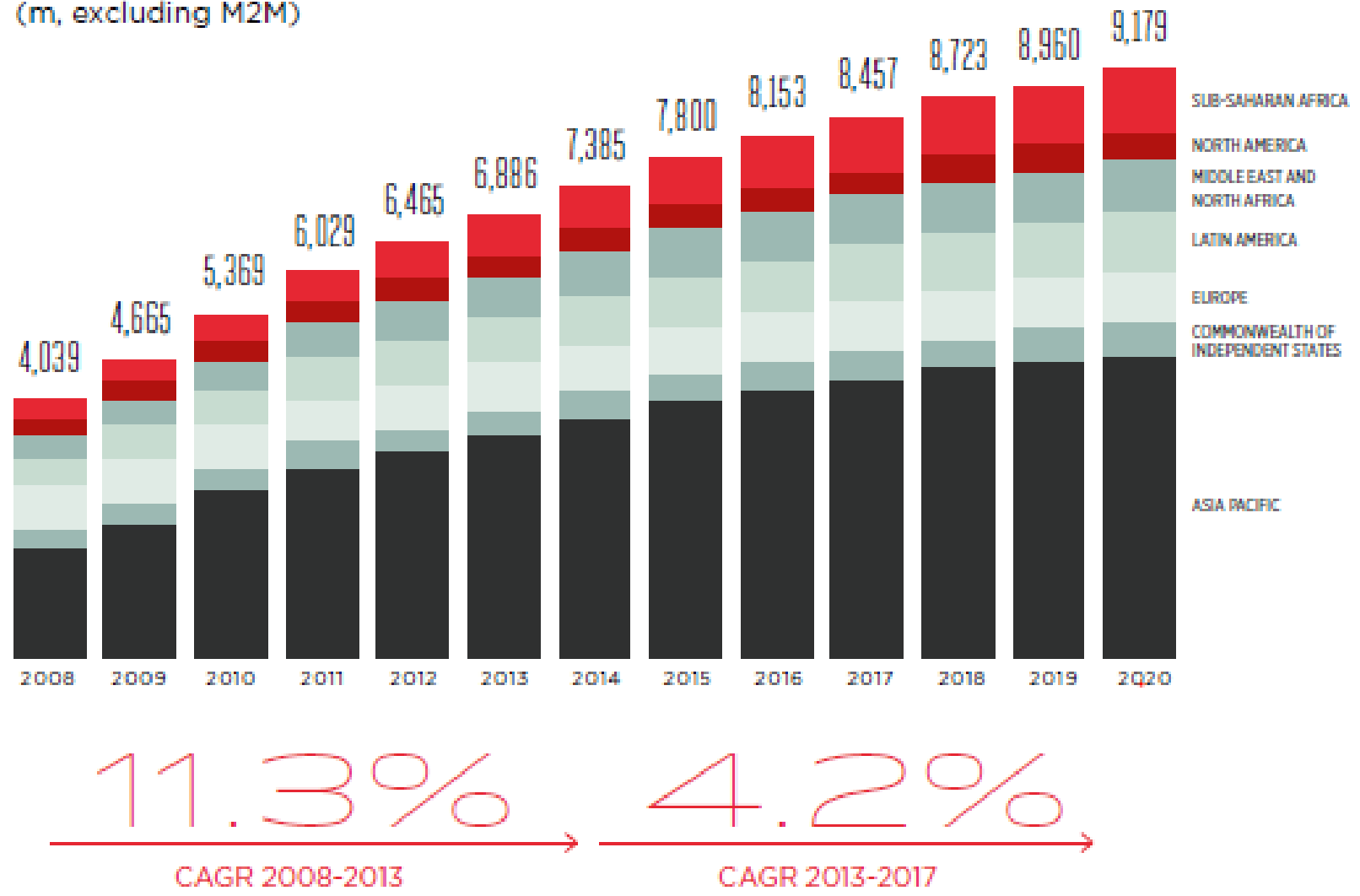

Source: $\underline{\text { http://www.gsma.com/mobileeconomy/archive/GSMA_ME_2014.pdf }}$ 


\section{Exhibit 5: Syniverse Office Locations}

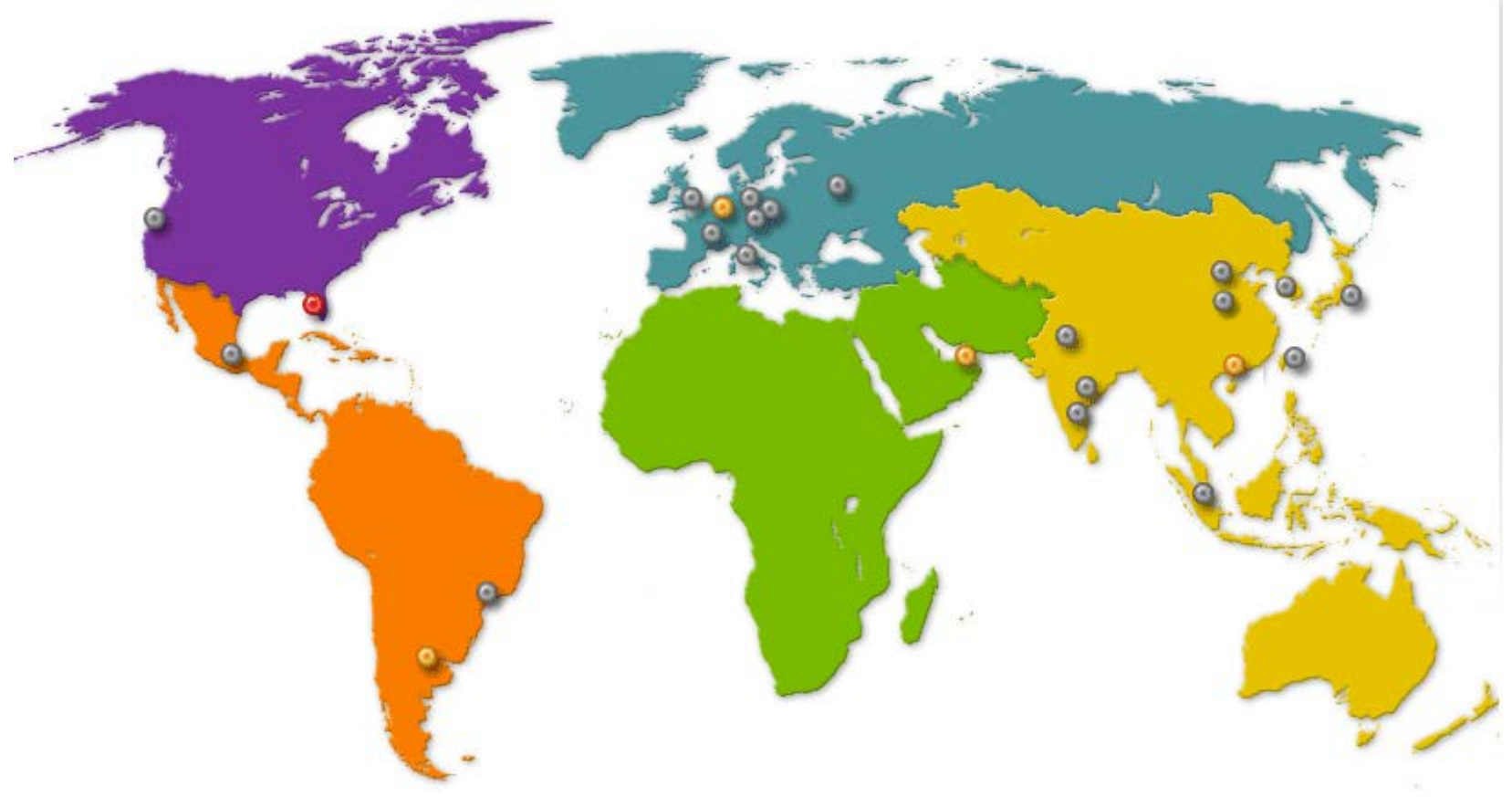

Source: https://www.syniverse.com/ 
MUMA CASE REVIEW

\title{
Exhibit 6: U.S. Short Code Processes
}

\author{
What is a Common Short Code (CSC)? \\ A Common Short Code, or CSC, is a short code which is common across many wireless service \\ providers in the U.S. It's the inter-carrier connec tion for your mobile application. All CSCs are 5 \\ or 6 digits in length and can be either random or select (vanity or easy to remember). The \\ Common Short Code Administrator (CSCA) or www. usshortcodes.com assigns CSCs to \\ applicants allowing them to be used for the same application across multiple wireless service \\ providers. ACSC is often called a brand's "mobile marketing address".
}

\section{What is a short code?}

A short code is a number to which an SMS or text message can be sent. A short code is fewer digits than a 10-digit telephone number. For example, a short code could be 54321 . A short code may be specific to one mobile operator or "common" and supported by all major mobile operators.

How do I know if a short code works with my wireless service provider?

Mobile applications that include a short code will identify networks with which the application works. If you still have questions, the best thing to do is to contact the company who is promoting the mobile application, or try to send the keyword "Help" to the CSC.

\section{Do CSCs work with all wireless service providers?}

In most cases, yes, all wireless service providers have the option of supporting each CSC and its associated application. The decision of whether or not to support a CSC is left to the sole discretion of the wireless service provider.

\section{How do CSCs work?}

A wireless subscriber is made aware of a CSC, whether through TV, radio, online or through an advertisement and asked to send a text message to the CSC. The wireless subscriber then addresses a text message to the CSC number (e.g. 74678) and enters text into the message as directed. Once the wireless subscriber sends the message, it is routed through the wireless service providers' network to the SMS messaging server. The wireless servic e provider's SMS messaging server then determines where to route the message based on the CSC and which application provider or brand supports/ corresponds to the CSC. The applic ation receives the message and routes it through the software application, which could include sending a confimation or follow-up message back to the wireless subscriber who originated the message.

\section{What kind of things can I do on my mobile phone with a CSC?}

A CSC allows an individual to engage and interact with a brand - to send text messages to a company's mobile applic ation including voting, polling, games, contests, coupons, mobile payments, and a variety of other exciting interactive applications. CSCs allow consumers to interact, communic ate and become involved.

\section{How do I lease a Common Short Code?}

To lease a CSC, an individual or company must first set up an account on www.usshortcodes.com. Once this is done, an applic ation for the lease of a CSC may be completed. The application will then be either approved or disapproved, and the applic ant will be notified by email.

\section{How much does it cost to lease a Common Short Code?}

A CSC is leased for a period of three (3), six (6) or twelve (12) months for a non refundable fee of $\$ 500$ per month for a "Random CSC"' and a nonrefundable fee of $\$ 1,000$ a month for a "Selected CSC". The entire lease payment must be paid before the CSC is assigned to the applicant and "registered".

Source: $\underline{\text { http://www.ctia.org/initiatives/common-short-codes }}$ 


\section{Exhibit 7: Representation of Network Connections with and without an Aggregator}
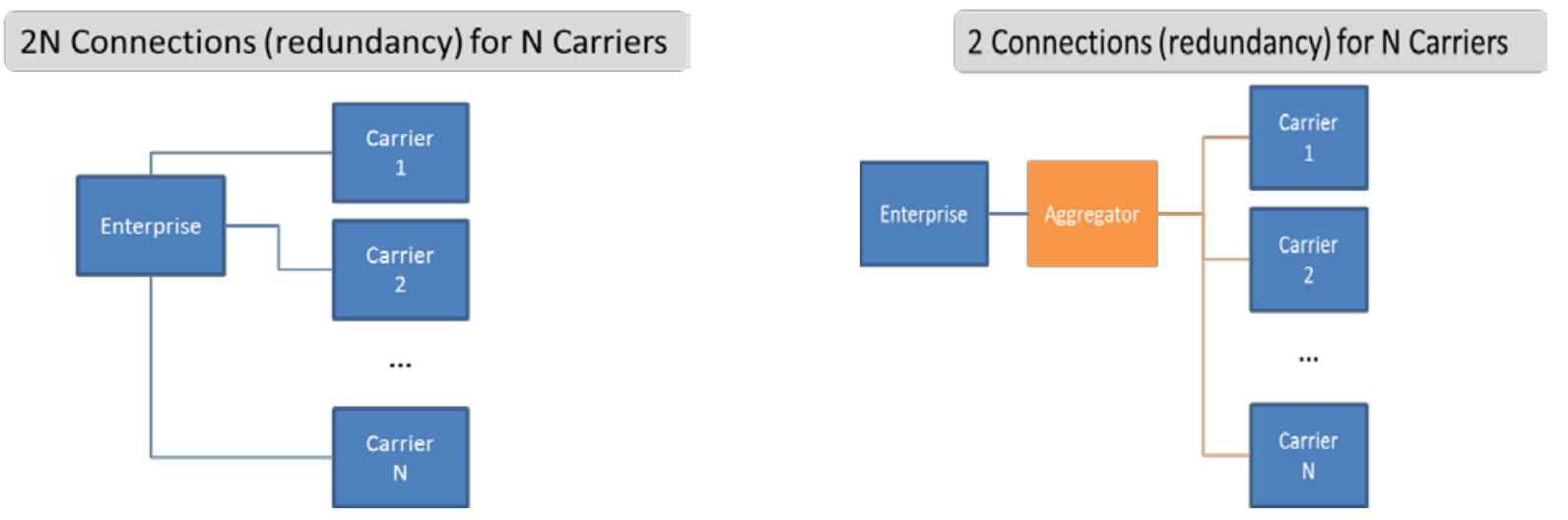

Source: http://mobilefomo.com/2015/04/types-context-enrich-mobile-marketing/ 


\section{Exhibit 8: Syniverse Mobile Engagement Product Sheet}

Syniverse Mobile

Engagement for

Customers enables

companies to create,

deploy, and manage

mobile campaigns across

channels in real time.
Innovations in mobile provide new opportunities for companies to reach their customers in hyperpersonalized ways, so reaching your customers in the mobile moment is more important than ever, The implementation of engaging mobile campaigns based on real-time data provides the opportunity to achieve contextual, and targeted communications with customers anytime, anywhere and on any device.

Syniverse Mobile Customer Engagement enables companies to create, deploy, and manage mobile campaigns across channels in real time. Our GUl-based cloud solution makes it easy for companies to deliver any type of mobile campaign, offering standard templates for quick deployment, or customizing templates for a new campaign type to be distributed via SMS, MMS, web, social networks, mobile app push notifications, and/or email.

Syniverse's global presence allows companies to reach nearly every mobile device, platform and network. Our Mobile Engagement solution empowers brands to enrich and extend business processes and enhance engagement so customers and employees can always be reached, anywhere in the world.

Benefits

- Leverage micro-location (i.e. beacons) and geo-location to reach customers in the mobile moment

- Update campaigns in real time to deliver interactive, personalized communications to customers

- Realize higher ROI via targeted reach, increased traffic and engagement

- Improve business efficiencies by using a single interface for multiple campaign types

\section{Features}

Syniverse Mobile Engagement for Customers offers more than 200 features and a suite of customizable applications in a cross-channel platform, including:

- Templates to easily fill in information and deploy campaigns

- Ability to upload customer data and opt-in information (long code, short code, web) against multiple data sources including CSV, web interface and APIs

- Fast deployed GUI-based tools

- API integration

- Professional services

- Reporting tools 


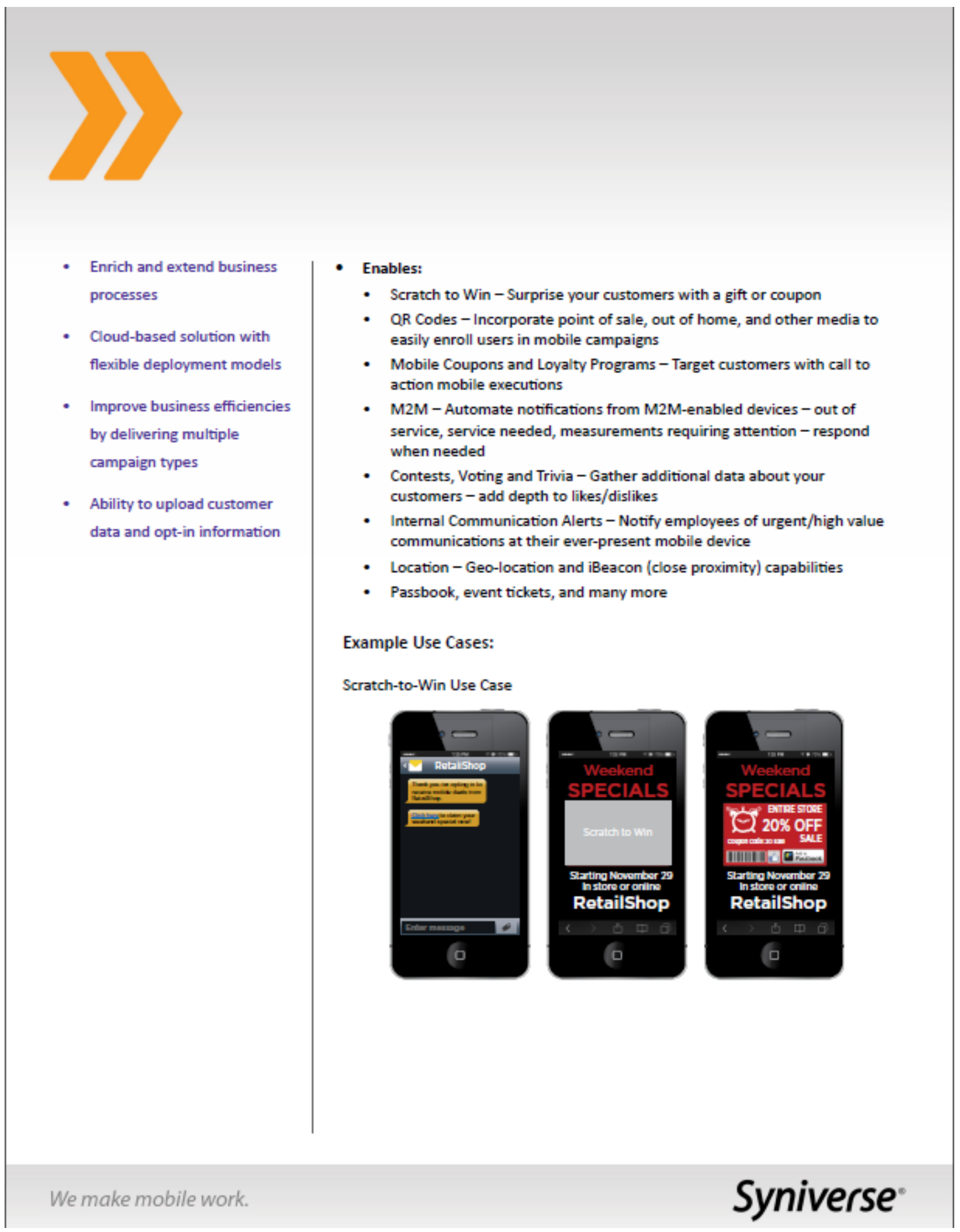




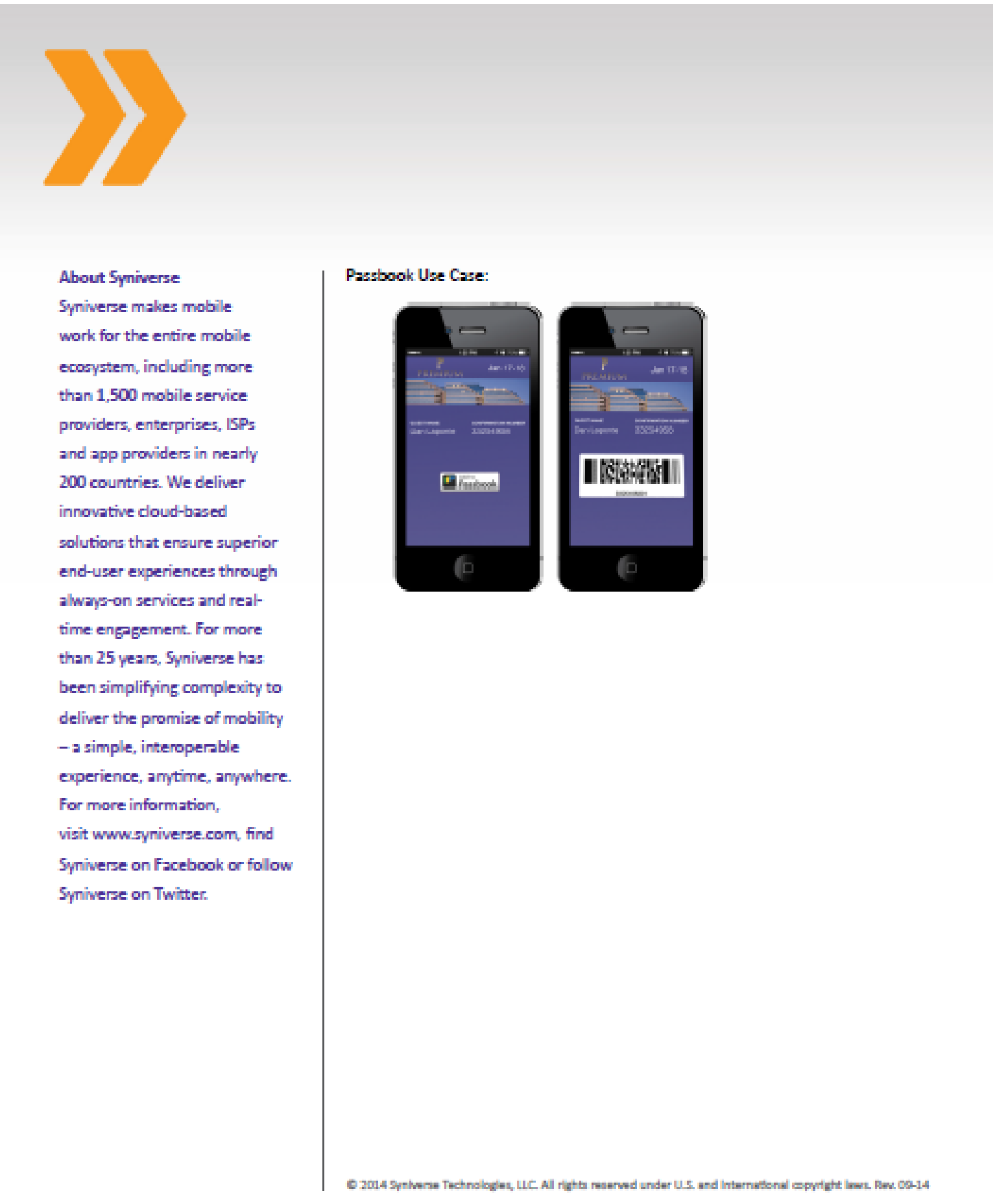

We make mobile work.

Syniverse

Source: https://www.syniverse.com/ 


\section{Exhibit 9: List of U.S. Short Code Providers}

\section{Find a Partner}

Find the right partner for your SMS campaign. Click on the partners listed below to see company bio and contact information

Our Premier Partners

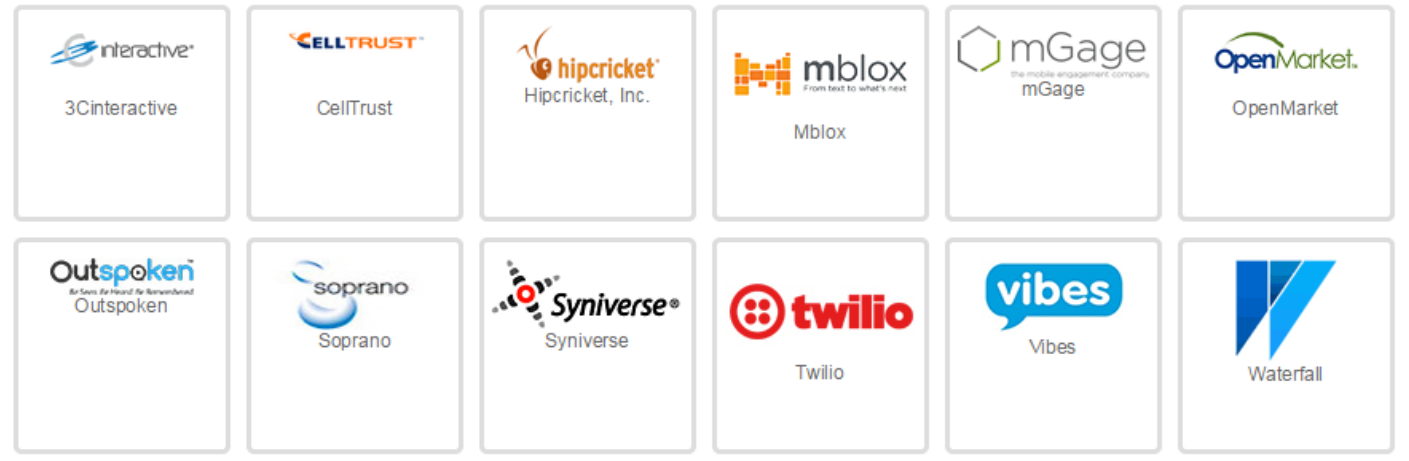

Source: http://www.ctia.org/initiatives/common-short-codes 


\section{Exhibit 10: Syniverse Infographic What to Look for when Choosing a Mobile Messaging Provider}

\section{What to Look for When Choosing a \\ Mobile Messaging Provider}
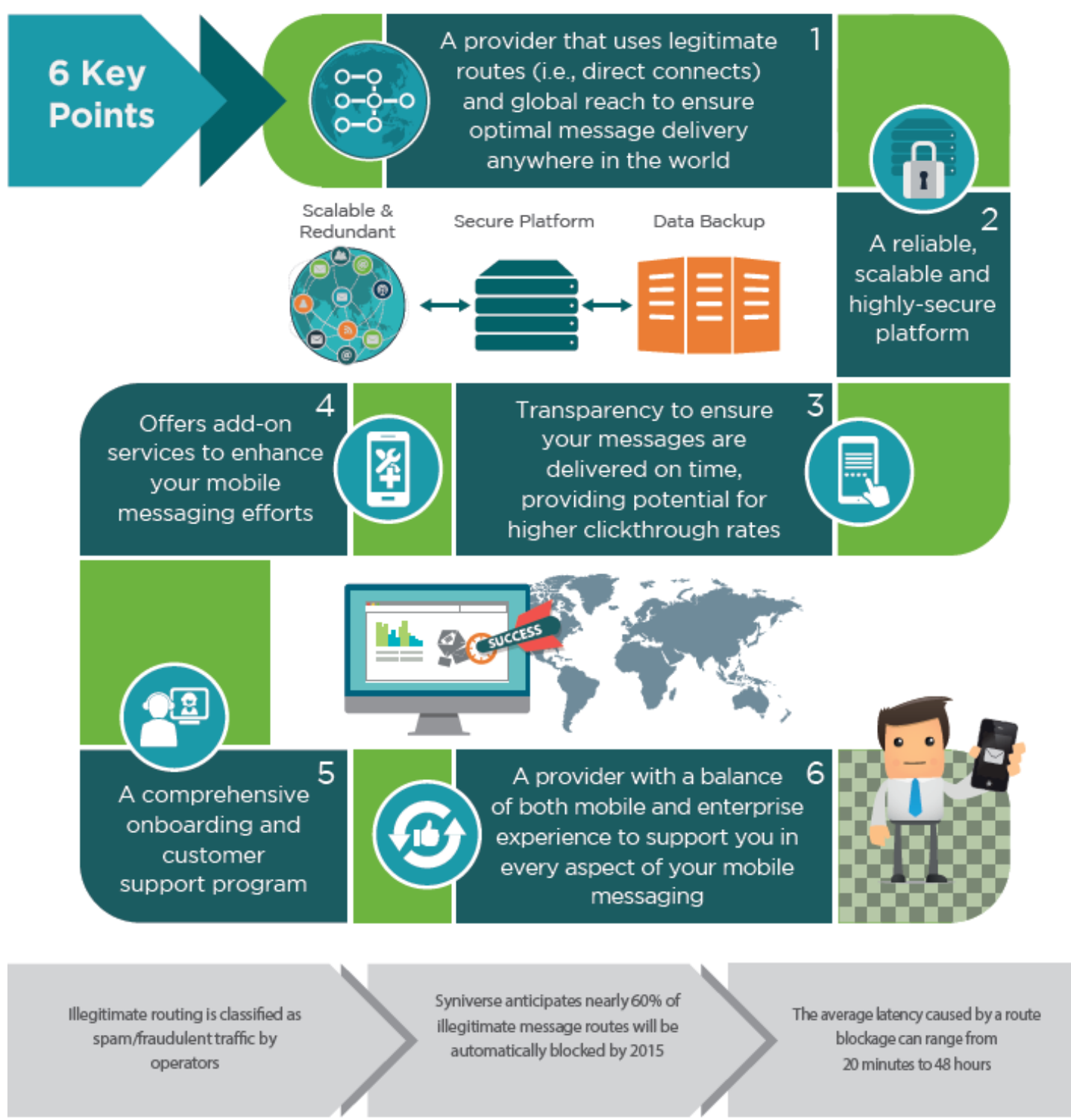

\section{Syniverse}

We make mobile work

Source: https://www.syniverse.com/ 


\section{Exhibit 11: A Taxonomy of Human Motivation from Intrinsic and Extrinsic Motivations: Classic Definitions and New Directions (Ryan \& Deci, 2000)}

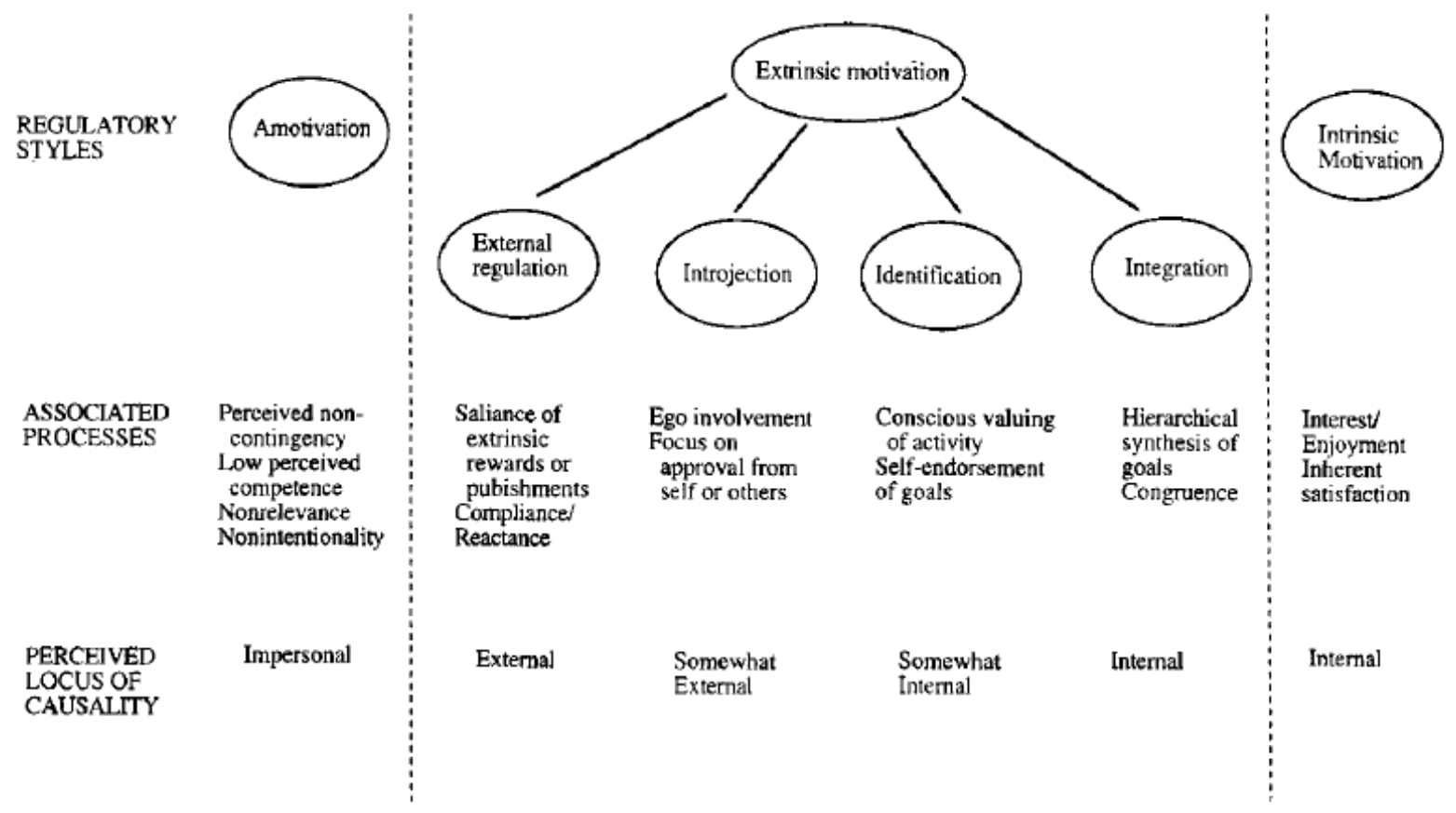

Source: http://www.sciencedirect.com/science/article/pii/S0361476X99910202 
Exhibit 12: Single Client Resonnance Model from Informing Business: Research and Education on a Rugged Landscape (Gill, 2010)

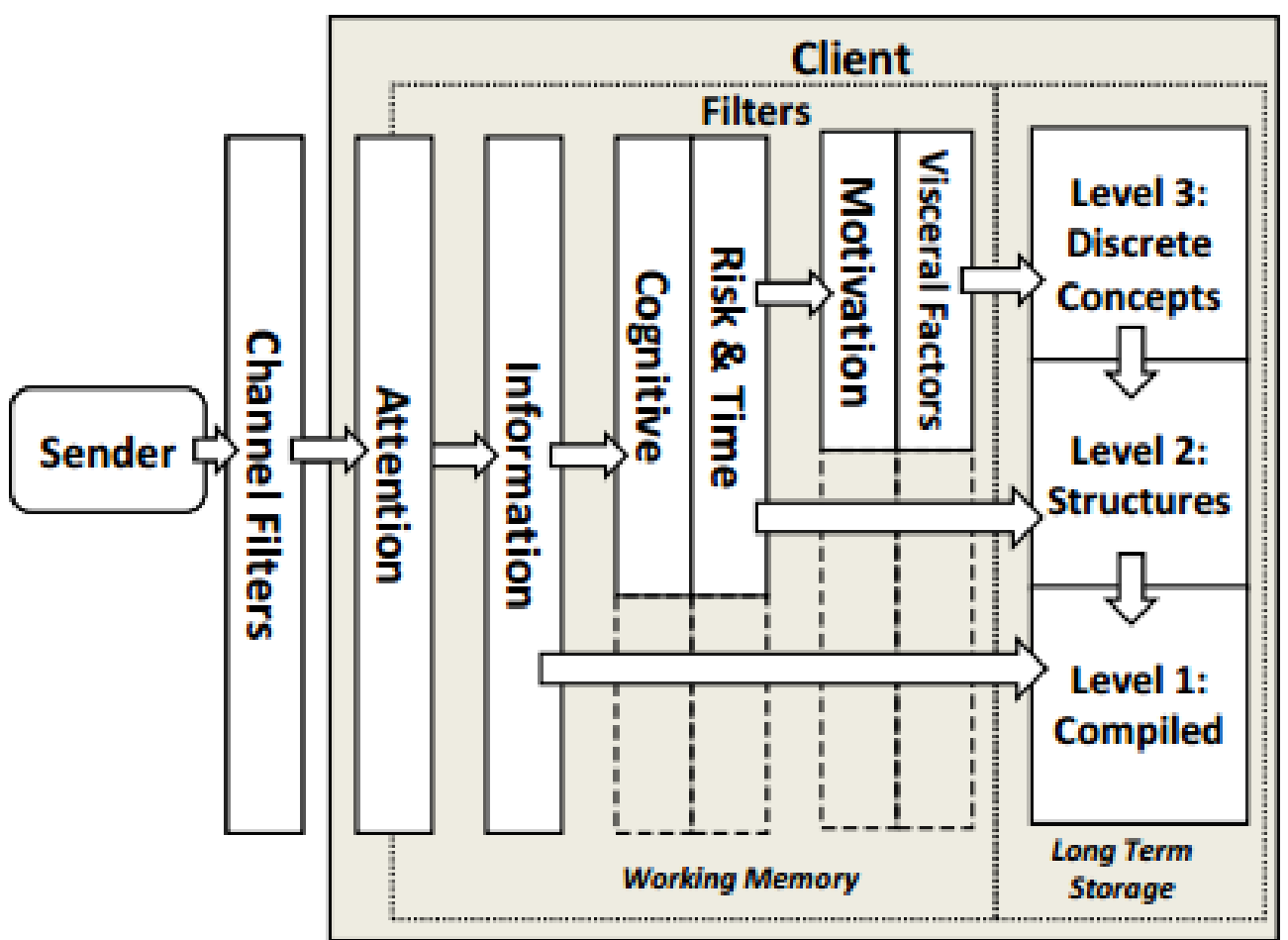

Source: http://www.grandon.com/publications/InformingBusiness.pdf 
Exhibit 13: Decomposable versus Interacting Contributions to Fitness from Informing Business: Research and Education on a Rugged Landscape (Gill, 2010)

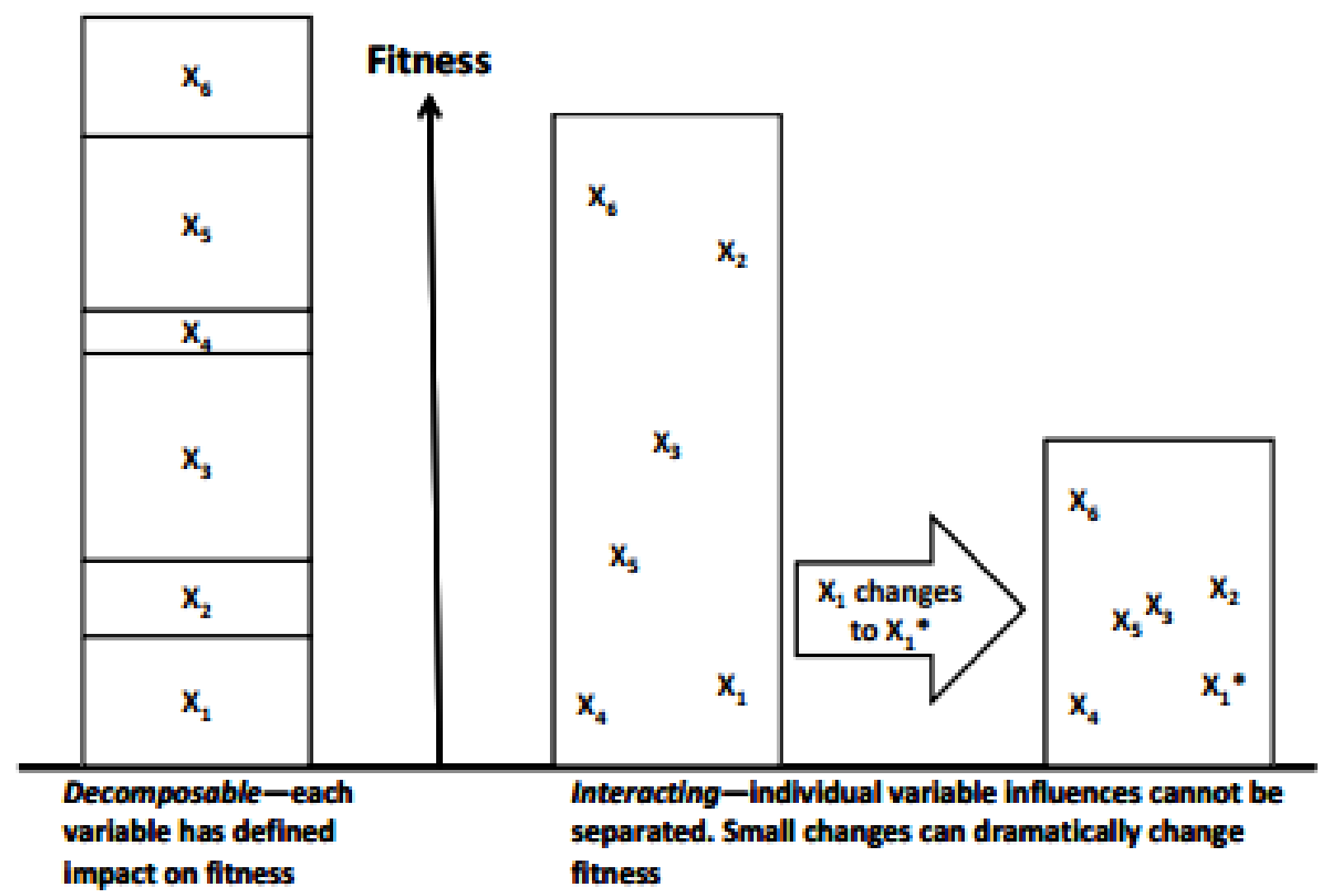




\section{Overall}

- Strong credible company

- Enterprise proven

- Carrier relationships

- Existing customer base

\section{Regional Expansion of SMS}

- Known product

- Established competitors in expansion regions

- Limited barriers to entry

- New sales resources

\section{Mobile Enable Enterprise Applications}

- Some success with in US

- Difficult to dislodge once deployed

- Limited brand awareness outside of telecommunications

- New sales skills required

\section{Other Distribution and Product Options}

- Sales channels

- Product combinations

Source: Developed by case writer

\begin{tabular}{|c|c|}
\hline 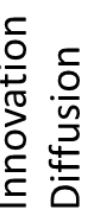 & 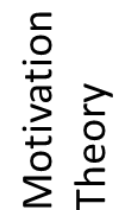 \\
\hline
\end{tabular}
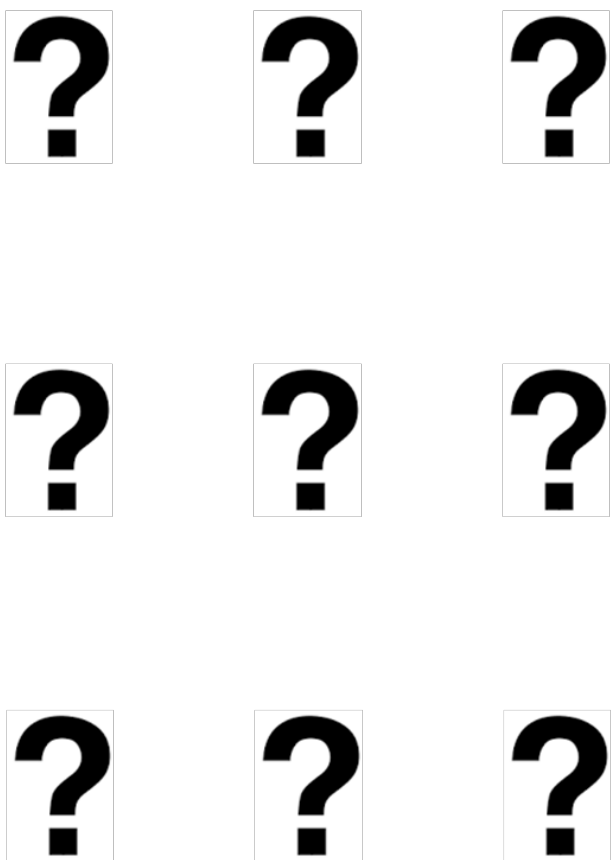